\title{
ANALISIS KAPASITAS DAYA DUKUNG PONDASI TIANG PANCANG DENGAN PEMBEBANAN VERTIKAL MENGGUNAKAN PROGRAM STAAD Pro V8i PADA PROYEK PEMBANGUNAN RUMAH SAKIT KELAS D KECAMATAN KINTAP KABUPATEN TANAH LAUT
}

\author{
${ }^{1)}$ Yuli Wahyudi \\ ${ }^{2)}$ Akhmad Gazali \\ ${ }^{3)}$ Fathurrahman \\ ${ }^{1)}$ Teknik Sipil Universitas Islam Kalimantan Muhammad Arsyad Al Banjari \\ E-mail : yuliwahyudi28@gmail.com \\ ${ }^{2)}$ Teknik Sipil Universitas Islam Kalimantan Muhammad Arsyad Al Banjari \\ E-mail : akhmadgazali51@gmail.com \\ ${ }^{3)}$ Teknik Sipil Universitas Islam Kalimantan Muhammad Arsyad Al Banjari \\ E-mail : fathurrahman75@gmail.com
}

\begin{abstract}
ABSTRAK
Daya dukungpondasi merupakan salah satu faktor yang penting untuk diperhitungkan dalam perencanaan dan pelaksanaan konstruksi. Daya dukung pondasi diharapkan mampu melebihi pembebanan vertikal bangunan, guna untuk menjaga kestabilan berdirinya suatu bangunan.

Dalam analisis daya dukung pondasi tiang pancang pada pembangunan Rumah Sakit Kelas D Kecamatan Kintap Kabupaten Tanah Laut menggunakan metode Meyerhof dan data penyelidikan tanah diperoleh dari hasil uji lapangan Cone PenetrationTest (Sondir). Sedangkan dalam analisis pembebanan vertikal menggunakan bantuan program STAAD Pro V8i (metode finite element).

Berdasarkan hasil perhitungan analisis daya dukung pondasi tiang pancang pada pembangunan Rumah Sakit Kelas D Kecamatan Kintap Kabupaten Tanah Laut diperoleh nilai kapasitas daya dukung ultimit pondasi sebesar 211,520 ton. Sedangkan hasil analisis pembebanan vertikal menggunakan program STAAD Pro V8i diperoleh nilai gaya vertikal maksimum sebesar 81,965 ton. Dari hasil kedua analisis tersebut dapat diperoleh nilai faktor keamanan pondasi sebesar 2,581 dan pondasi tersebut dapat disimpulkan aman dalam menahanpembebanan vertikal.
\end{abstract}

Kata Kunci:Kapasitas Daya Dukung, Pondasi Tiang Pancang,Pembebanan Vertikal, STAAD Pro V8i.

\begin{abstract}
Foundation carrying capacity is one of the important factors to be taken into account in planning and carrying out construction. Bearing capacity is expected to be able to exceed the vertical loading of buildings, in order to maintain the stability of the establishment of a building. In the analysis of carrying capacity of pile foundations in the construction of Class D Hospital in Kintap District Tanah Laut Regency using the Meyerhof method and ground investigation data obtained from the results of the Cone Penetration Test field test (Sondir). Whereas in the vertical loading analysis using the help of the STAAD Pro V8i program (finite element method).

Based on the results of the calculation of the analysis of carrying capacity of the pile foundation in the construction of Class D Hospital in Kintap District Tanah Laut Regency, the value of ultimate bearing capacity of the foundation is 211,520 tons. While the results of vertical loading analysis using the STAAD Pro V8i program obtained a maximum vertical force value of 81.965 tons. From the results of the two analyzes can be obtained the value of the foundation safety factor of 2.581 and the foundation can be concluded to be safe in holding vertical loading.
\end{abstract}

Keywords: Carrying Capacity, pile foundation, Vertical Loading, STAAD Pro V8i. 


\section{PENDAHULUAN}

\section{Latar Belakang}

Secara umum pondasi di definisikan sebagai bangunan dalam tanah yang meneruskan beban yang berasal dari berat bangunan itu sendiri dan bangunan luar yang bekerja ke lapisan tanah di bawahnya. Dalam rangka pembangunan gedung dengan ditinjau dari segi keamanan suatu bangunan konstruksi, perhitungan daya dukung pondasi tiang sangat penting dalam perencanaan pembangunan. Perhitungan tersebut bertujuan untuk mengetahui kemampuan tiang dalam tanah untuk menahan beban struktur atas. Dalam penelitian ini pembebanan struktur atas yang dianalisis adalah pembebanan vertikal. Berdasarkan analisis daya dukung pondasi tiang dan analisis pembebanan vertikal tersebut, dapat diperoleh nilai faktor keamanan pondasi tiang. Nilai faktor keamanan tersebut untuk mengetahui tingkat keamanan bangunan.Perencanaan pondasi perlu di perhitungkan besarnya beban yang bekerja dan juga daya dukung tanah setempat, karena apabila pondasi yang di rencanakan tidak mencapai tanah keras, maka akan terjadi penurunan yang tidak merata yang nantinya dapat mengakibatkan kerusakan pada bangunan struktur atasnya, dimana analisa pada struktur atas dalam penelitian ini menggunakan program STAAD Pro V8i. Penggunaan program STAAD Pro V8i tersebut sangat penting untuk mengetahui besarnya beban yang bekerja pada bangunan struktus atas, sehingga dapat diketahui apakah kapasitas daya dukung tiang pancang pada pembangunan Rumah Sakit Kelas D Kecamatan Kintap Kabupaten Tanah Laut tersebut sudah mampu atau tidak dalam menahan beban struktur diatasnya dengan mengetahui faktor keamanannya, dimana perhitungan kapasitas daya dukung tiang berdasarkan uji lapangan Cone Penetration Test (Sondir).

\section{Rumusan Masalah}

Rumusan masalah dalam rangkaian penelitian skripsi ini adalahanalisis kapasitas daya dukung pondasi tiang pancang dengan menggunakan metode Meyerhof, analisis pembebanan dengan menggunakan aplikasi program STAAD Pro V8i, dan perbandingan antara analisis kapasitas daya dukung pondasi tiang pancang dan analisis pembebanan sehingga menghasilkan nilai faktor keamanan

\section{Tujuan dan Manfaat Penelitian}

Tujuan dalam penellitian skripsi ini adalah menganalisis daya dukung pondasi tiang pancang, menganalisis pembebanan menggunakan aplikasi program STAAD Pro V8i, dan mengetahui perbandingan antara analisis kapasitas daya dukung pondasi tiang pancang dan analisis pembebanan sehingga menghasilkan nilai faktor keamanan.Manfaat dalam penelitian skripsi ini adalahuntuk mengetahui faktor keamanan pondasi tiang pancang, dan sebagai bahan referensi untuk menghitung kapasitas daya dukung tiang pancang pada kondisi dan permasalahan yang sama.

\section{Batasan Masalah}

Adapun batasan masalah dalam penelitian skripsi ini adalah data pendukung penyelidikan menggunakan data Sondir sebanyak 2 (dua) titik, analisis daya dukung tiang pancang berdasarkan nilai pembebanan gaya vertikal maksimum, metode perhitungan daya dukung tiang menggunakan metode Meyerhof. 
JURNAL KACAPURI

JURNAL KEILMUAN TEKNIK SIPIL

Volume 1 Nomor 2 Edisi Desember 2018

\section{TINJAUAN PUSTAKA}

\section{Tiang Dukung dan Tiang Gesek}

Ditinjau dari cara mendukung beban, tiang dapat dibagi menjadi 2 macam terlihat pada gambar 1dibawah ini.

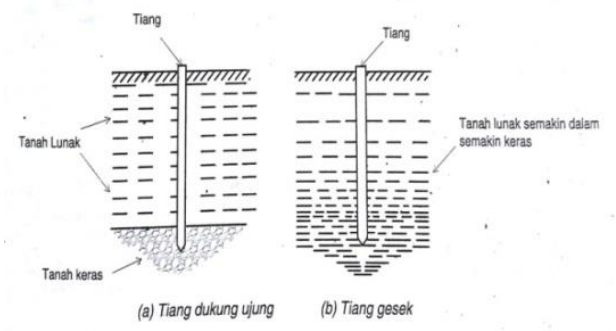

Gambar 1. Tiang ditinjau dari cara mendukung beban (Tomlinson,1977)

\section{Kapasitas Daya DukungTiang Tunggal}

Kapasitas daya dukung tiang terdiri dari kapasitas dukung ujung tiang (Qp) dan kapasitas dukung selimut tiang (Qs), yang dapat dilihat pada gambar 2 dibawah ini.

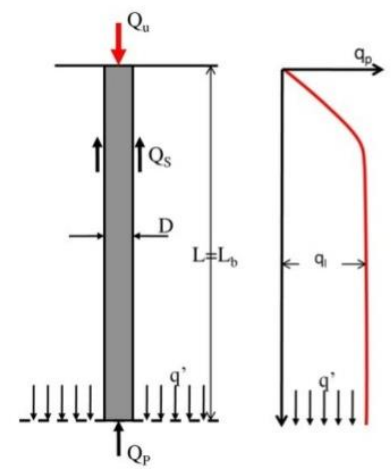

Gambar 2. Kapasitas dukung tiang (Meyerhof, 1976)

\section{Kapasitas Daya Dukung Ultimit Tiang Tunggal}

Kapasitas dukung ultimit tiang $(\mathrm{Qu})$, dihitung dengan persamaan umum :

$\mathrm{Qu}=\mathrm{Qb}+\mathrm{Qs}=\mathrm{Ab} f b+\mathrm{As} f s(\mathrm{Kg})$

dengan keterangan :

$\mathrm{Qb}=$ Kapasitas tahanan di ujung tiang $(\mathrm{kg})$

Qs = Kapasitas tahanan gesek $(\mathrm{kg})$

$\mathrm{Ab}=$ Luas ujung bawah tiang $(\mathrm{cm} 2)$

As $=$ Luas selimut tiang $(\mathrm{cm} 2)$

$f b=$ Tahanan ujung satuan tiang $(\mathrm{kg} / \mathrm{m} 2)$

$f s=$ Tahanan gesek satuan tiang $(\mathrm{kg} / \mathrm{m} 2)$

\section{Kapasitas Daya Dukung Vertikal Yang Dijinkan}

Daya dukung ultimate netto tiang tunggal $(\mathrm{Qu})$, adalah jumlah dari daya dukung ujung bawah ultimit $(\mathrm{Qb})$ dan daya dukung gesek tiang ultimit $(\mathrm{Qs})$ antara dinding tiang dan tanah sekitarnya dikurangi dengan berat sendiri tiang. Bila dinyatakan dalam persamaan, maka :

$\mathrm{Qu}=\mathrm{Qb}+\mathrm{Qs}-\mathrm{Wp}$

Keterangan:

$\mathrm{Wp}=$ Berat sendiri tiang

$\mathrm{Qu}=$ Kapasitas ultimit netto

Menghitung daya dukung tiang tunggal, dengan data tanah yang berdasarkan data uji lapangan Cone Penetration Test (Sondir). Dengan ini kapasitas daya dukung ultimit tiang dapat dihitung dengan menggunakan metode Meyerhof dengan rumus sebagai berikut :

$\mathrm{Qu}=\mathrm{qc} \cdot \mathrm{Ap}+\mathrm{JHL} \cdot \mathrm{O}$ 
Keterangan:

$\mathrm{Qu}$ = Kapasitas daya dukung ultimit tiang

$\mathrm{qc}=$ Tahanan ujung sondir

Ap = Luas penampang tiang

$\mathrm{JHL}=$ Jumlah hambatan lekat

$\mathrm{O}=$ Keliling tiang

\section{Faktor Aman Tiang Pancang}

Dalam penelitian ini faktor keamanan yang digunakan diperoleh dari hasil pembagian antara kapasitas daya dukung tiang dengan pembebanan gaya vertikal maksimum, secara matematis dapat dituliskan sebagai berikut:

$\mathrm{FK}=\frac{Q_{u l t}}{P_{\max }}$

Keterangan:

FK $\quad$ Faktor keamanan

Qult $\quad=$ Kapasitas daya dukung tiang

$\mathrm{P}_{\max } \quad=$ Beban gaya vertikal maksimum

\section{Program STAAD Pro V8i}

STAAD adalah salah satu program analisa program analisa struktur yang pada saat ini telah banyak dipakai diseluruh dunia. STAAD menggunakan teknologi yang paling modern dalam rekayasa elemen hingga, dengan metode input data berbasis object oriented.Program ini dikembangkan oleh tim dengan pengalaman lebih dari 20 tahun riset yang diadakan di USA, Kanada, dan eropa dalam merumuskan metode ini.Kelebihan yang sangat dominan yang dimilki oleh STAAD adalah adalah kemudahan dalam penggunaannya. GUI (Graphical User Interface) dirancang sedemikian rupa agar user/pengguna lebih mudah menggunakan aplikasi dari program ini.

\section{METODE PENELITIAN}

\section{Pengumpulan Data}

Data yang diperlukan yaitu hasil uji penyelidikan tanah, dan detail gambar kerja.

\section{Hasil Uji Penyelidikan Tanah}

Pada pembangunan Rumah Sakit Kelas D Kecamatan Kintap Kabupaten Tanah Laut ini, penyelidikan tanah yang dilakukan adalah penyelidikan tanah dengan Cone Penetration Test (Sondir).

\section{Gambar Kerja}

Gambar kerja pada bangunan Rumah Sakit Kelas D Kecamatan Kintap Kabupaten Tanah Laut meliputi: Profil baja yang di pakai untuk atap dan sebagian area atap menggunakan plat dak beton serta balok, kolom menggunakan beton, denah ruangan yang akan di bangun dan fungsi ruangan tersebut secara detail, bagian ruangan yang akan dibuat plat lantai beton.

\section{Spesifikasi Tiang Pancang}

Spesifikasi tiang pancang yang digunakan adalahtiang pancang mini pile ukuran square pile $20 \mathrm{~cm}$ x $20 \mathrm{~cm}$, modul tiang pancang terdiri dari Bottom $=6 \mathrm{~m}$, Top $=6 \mathrm{~m}$ dengan panjang total $12 \mathrm{~m}$, dengan mutu beton tiang pancang adalah K400.

\section{Analisis Pembebanan}

Pada analisis pembebanan menggunakan program aplikasi software komputer yaitu STAAD Pro V8i. 
JURNAL KACAPURI

JURNAL KEILMUAN TEKNIK SIPIL

Volume 1 Nomor 2 Edisi Desember 2018

\section{Analisis Kapasitas Daya Dukung Tiang Pancang}

Dalam menganalisis kapasitas daya dukung pondasi tiang pancang, beban yang bekerja pada kolom harus diketahui terlebih dahulu. Untuk memperoleh nilai tersebut dilakukan analisis menggunakan metode Mayerhof.

Diagram alir penelitian dapat dilihat pada Gambar 3 sebagai berikut :

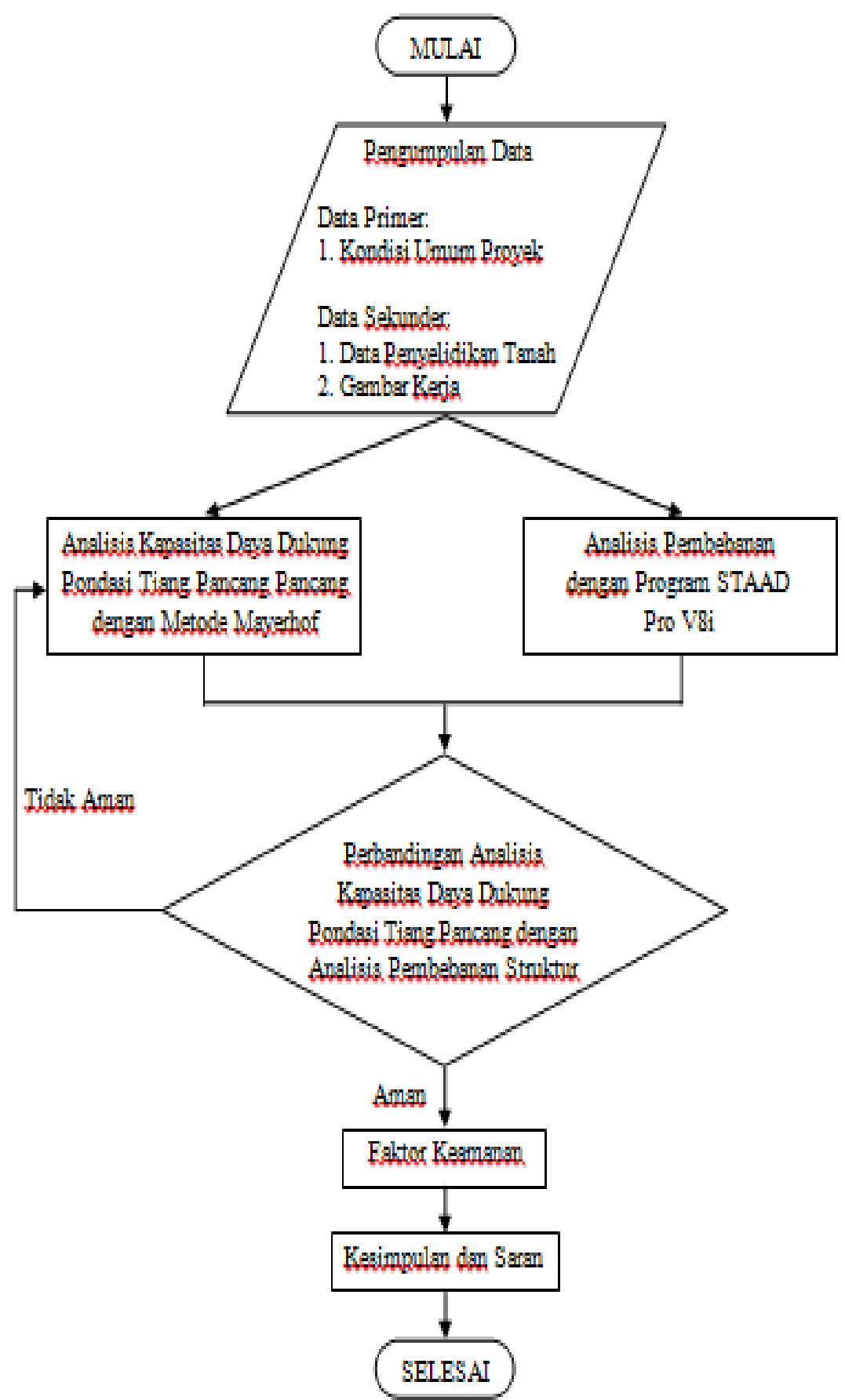

Gambar 3. Diagram Alir Metode Penelitian 
JURNAL KACAPURI

JURNAL KEILMUAN TEKNIK SIPIL

Volume 1 Nomor 2 Edisi Desember 2018

\section{HASIL DAN PEMBAHASAN}

\section{Hasil Pembebanan STAAD Pro V8i}

Berikut ini tampilan rangka bangunan pada program STAAD Pro V8i pada tampilan tampak depan terlihat pada gambar 4 dibawah ini.

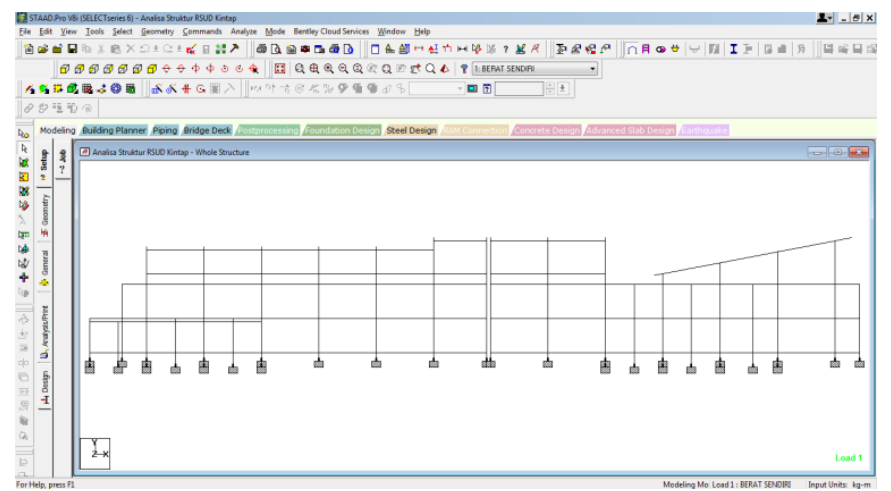

Gambar 4. Tampilan Tampak Depan

Berikut adalah tampilan tampak atas rangka bangunan pada program STAAD Pro V8i terlihat pada gambar 5 dibawah ini.

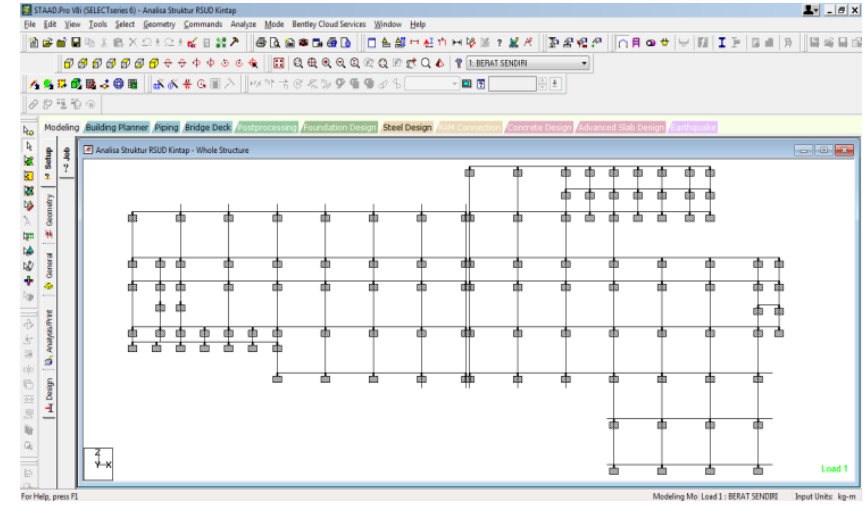

Gambar 5. Tampak Atas

Berikut adalah tampilan 3D rangka bangunan pada program STAAD Pro V8i terlihat pada gambar 6 dibawah ini.

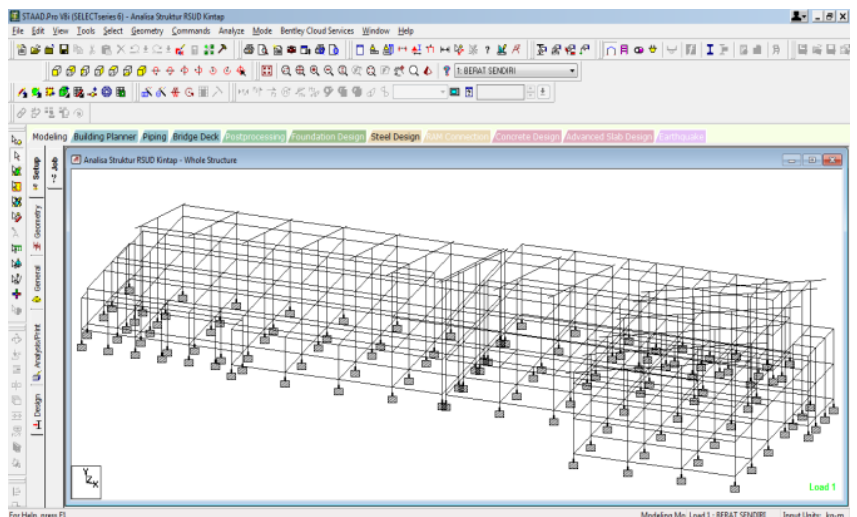

Gambar 6. Tampilan 3D

Berikut adalah tampilan rangka bangunan pada program STAAD Pro V8i pada saat gaya aksial terlihat pada gambar 7 dibawah ini. 
JURNAL KACAPURI

JURNAL KEILMUAN TEKNIK SIPIL

Volume 1 Nomor 2 Edisi Desember 2018

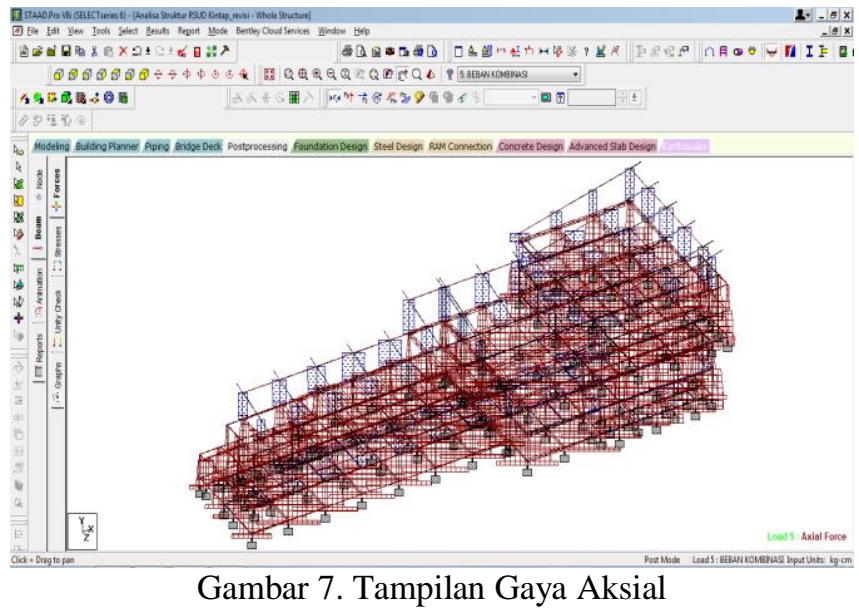

Dibawah ini adalah hasil pembebanan pada program STAAD Pro V8i terlihat pada gambar 8 dibawah ini.

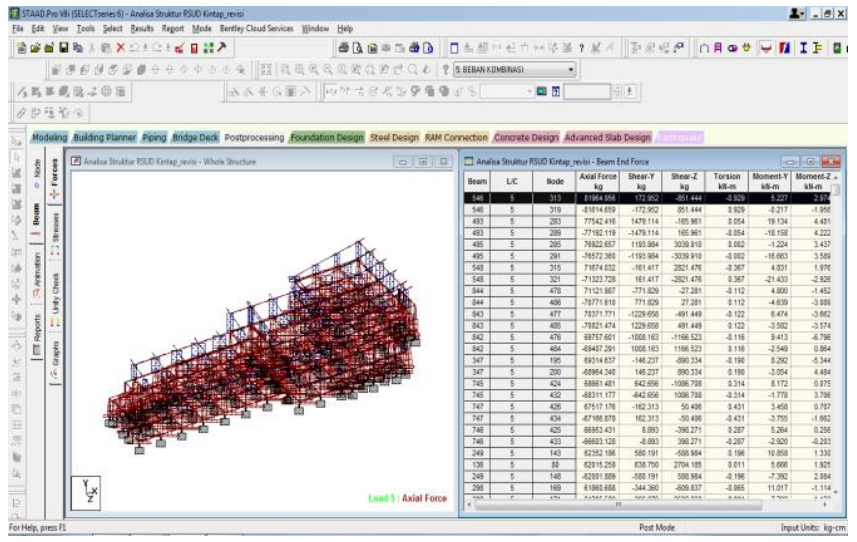

Gambar 8. Hasil Pembebanan

Berikut adalah tampilan hasil dari beban Axial Force (beban vertikal maksimum) pada program STAAD Pro V8i terlihat pada gambar 9 dibawah ini.

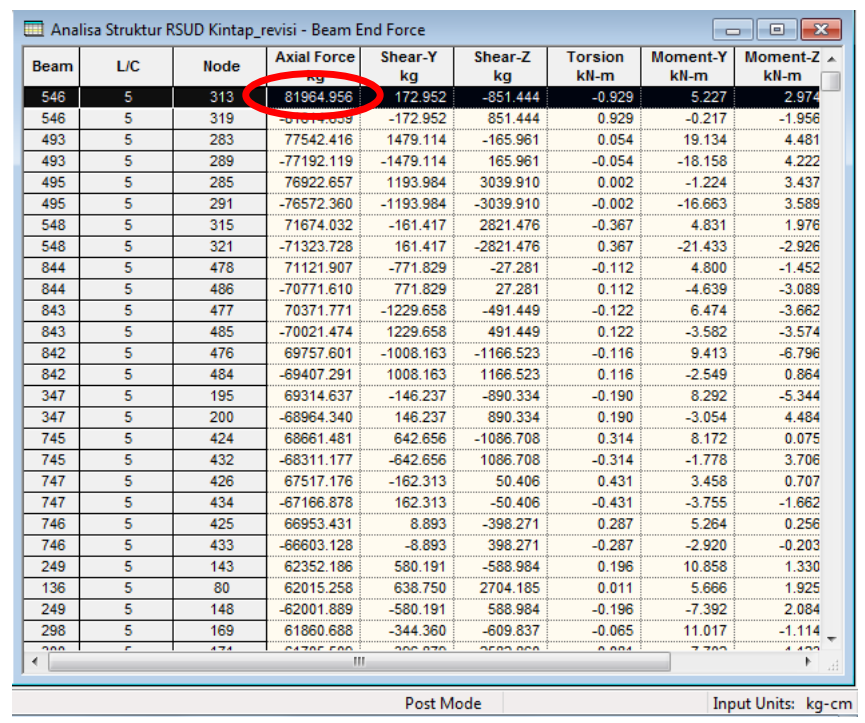

Gambar 9. Beban Axial Force (Beban Vertikal Maksimum) 
JURNAL KACAPURI

JURNAL KEILMUAN TEKNIK SIPIL

Volume 1 Nomor 2 Edisi Desember 2018

Dari gambar tersebutdiatasdidapat nilai Axial Force (beban vertikal maksimum) sebesar $81964,956 \mathrm{~kg}=81,965$ ton.

\section{Analisis Kapasitas Daya Dukung Tiang Tunggal}

Kapasitas dukung tiang terdiri dari kapasitas dukung ujung tiang (Qp) dan kapasitas dukung selimut tiang (Qs).

\section{Data Sondir}

Dari hasil sondir yang dilakukan di site didapat data-data tanah di lokasi perencanaan seperti terlihat pada tabel 1 dibawah ini.

Tabel 1. Data Hasil Sondir

\begin{tabular}{|c|c|c|c|c|}
\hline No & Kode Titik & $\begin{array}{c}\text { Kedalaman } \\
(\mathrm{m})\end{array}$ & $\begin{array}{c}\mathrm{q}_{\mathrm{c}} \text { Maks } \\
\left(\mathrm{Kg} / \mathrm{cm}^{2}\right)\end{array}$ & $\begin{array}{c}\text { JHP } \\
(\mathrm{Kg} / \mathrm{cm})\end{array}$ \\
\hline 1 & $\mathrm{~S}-1$ & 9.80 & 250 & 1394.00 \\
\hline 2 & $\mathrm{~S}-2$ & 14.00 & 250 & 1520.00 \\
\hline
\end{tabular}

\section{Kapasitas Daya Dukung Ultimate Tiang ( Qu )}

1. Perhitungan Daya Dukung Tiang Pancang Berdasarkan Data Sondir

Dari 2 titik sampel pemeriksaan sondir yang dipilih secara acak dapat diketahui parameterparameter fisik tanah yang nilai konus $\left(\mathrm{q}_{\mathrm{c}}\right)$ dan jumlah hambatan lekat atau total friksi (JHP). Sedangkan dari dimensi profil tiang pancang didapat dimensi luas penampang (A) dan keliling tiang $(\mathrm{O})$.

$\mathrm{Q}_{\mathrm{u}}=\left(\mathrm{q}_{\mathrm{c}} \times \mathrm{A}\right)+(\mathrm{JHP} \times \mathrm{O})$

$\mathrm{A}=20 \times 20=400 \mathrm{~cm}^{2}$

$\mathrm{O}=4 \times 20=80 \mathrm{~cm}$

2. Perhitungan Titik Sondir 1

Jika $\mathrm{q}_{\mathrm{c}}=250 \mathrm{~kg} / \mathrm{cm} 2, \mathrm{JHP}=1394.00 \mathrm{~kg} / \mathrm{cm}$, didapat :

$\mathrm{Q}_{\mathrm{u}}=\left(\mathrm{q}_{\mathrm{c}} \times \mathrm{A}\right)+(\mathrm{JHP} \times \mathrm{O})$

$\mathrm{Q}_{\mathrm{u}}=(250 \mathrm{Kg} / \mathrm{cm} 2 \times 400 \mathrm{~cm} 2)+(1394.00 \times 80)$

$=100.000 \mathrm{~kg}+111.520 \mathrm{~kg}$

$=211.520 \mathrm{~kg}$

$$
=211,520 \text { ton }
$$

3. Perhitungan Titik Sondir 2

Jika $\mathrm{q}_{\mathrm{c}}=250 \mathrm{~kg} / \mathrm{cm} 2, \mathrm{JHP}=1520.00 \mathrm{~kg} / \mathrm{cm}$, didapat :

$\mathrm{Q}_{\mathrm{u}}=\left(\mathrm{q}_{\mathrm{c}} \times \mathrm{A}\right)+(\mathrm{JHP} \times \mathrm{O})$

$\mathrm{Q}_{\mathrm{u}}=(250 \mathrm{Kg} / \mathrm{cm} 2 \times 400 \mathrm{~cm} 2)+(1520.00 \times 80)$

$=100.000 \mathrm{~kg}+121.600 \mathrm{~kg}$

$=221.600 \mathrm{~kg}$

$=221,600$ ton

Maka $Q_{u}$ rencana yang digunakan yang terkecil, yaitu $Q_{u}$ rencana pada titik sondir 1 yaitu 211,520 ton.

Berdasarkan analisis pembebanan gaya vertikal maksimum STAAD Pro dan analisis kapasitas daya dukung pondasi tiang pancang akan mendapatkan nilai faktor keamanan sebagai berikut terlihat pada tabel 2 dibawah ini.

Tabel 2. Faktor Keamanan

\begin{tabular}{|c|c|}
\hline Kapasitas Daya Dukung Tiang Tunggal & $\begin{array}{l}\text { Pembebanan Gaya Vertikal } \\
\text { Program STAAD PRO V8i }\end{array}$ \\
\hline 211,520 ton & $\mathrm{Q}_{\mathrm{u}}=81,965$ ton \\
\hline \multicolumn{2}{|c|}{$\mathrm{FK}=211,520 / 81,965=2,581$} \\
\hline \multicolumn{2}{|c|}{ Jadi, Faktor Keamanannya adalah sebesar 2,581 } \\
\hline
\end{tabular}




\section{PENUTUP}

\section{Kesimpulan}

Analisis kapasitas daya dukung pondasi tiang pancang pada Pembangunan Rumah Sakit Kelas D Kecamatan Kintap Kabupaten Tanah Laut dengan menggunakan metode Mayerhof diperoleh daya dukung ultimit $\left(\mathrm{Q}_{\mathrm{u}}\right)$ sebesar 211,520 ton. Analisis pembebanan pada Pembangunan Rumah Sakit Kelas D Kecamatan Kintap Kabupaten Tanah Laut menggunakan aplikasi Program STAAD Pro V8i diperoleh nilai gaya vertikal maksimum pada kolom sebesar 81,965 ton.Perbandingan antara nilai analisis kapasitas daya dukung pondasi tiang pancang dan analisis pembebanan gaya vertikal menghasilkan nilai faktor keamanan (FK) adalah sebesar 2,581.

\section{Saran-saran}

Berdasarkan hasil analisis ini, adapun beberapa saran yaitu: Hasil penelitian ini masih jauh dari kesempurnaan, sehingga perlu dilakukan penelitian untuk analisis pada permasalahan yang sama.Untuk menyimpulkan dari hasil analisis pembebanan struktur perlu menggunakan bantuan seperti SAP 2000, ANSYS, atau aplikasi struktur lainnya.Sebaiknya metode yang digunakan untuk perhitungan daya dukung teoritis pada penelitian selanjutnya dapat menggunakan beberapa metode selain metode Meyerhof sehingga dapat diperoleh nilai daya dukung yang mendekati keadaan real di lapangan.

\section{DAFTAR PUSTAKA}

Das, Braja M. 2011. Principles of Foundation Engineering,SI: Seventh Edition.

Peraturan Pembebanan Indonesia Untuk Gedung. 2015. Yayasan Lembaga Penyelidikan Masalah Bangunan. Bandung.

Muhammad, Gusti Muhajir. 2018. Perhitungan Kapasitas Daya Dukung Tiang Pancang Pada Gedung Kejaksaan Tinggi Kalimantan Timur.Samarinda.

Mamangkey, Victor. 2018. Analisis Pondasi Tiang Pancang Pada Silo Semen Tonasa.Manado

Hardiyatmo, Harry Christady. 2008. Teknik Pondasi 2.Gadjah Mada University Press. Yogyakarta.

Hardiyatmo, Harry Christady. 2011. Teknik Pondasi 2: Analisa Dan Perancangan Fondasi II. Gadjah Mada University Press . Yogyakarta.

Tomlinson, MJ. (1977; 1944). Pile Design and Construction Practice. The Garden City Press Limited, Lechworth, Hertfordshire SG6 1JS

Firdaus, Muhammad Alkaf. 2005. STAAD 2004 Untuk Orang Awam. Maxikom. Palembang.

Meyerhof, GG. 1956. Penetration Tests and Bearing Capacity of Cohesionless Soils. JSMFD, ASCE, Vol 82 SM, pp 1-19.

Meyerhof, GG. 1976. Penetration Tests and Bearing Capacity of Cohesionless Soils: Bearing Capacity and Settlement of Pile Foundations, ASCE Journal of Geotechnical Eng. Div. Vol 5, No 4, pp. 225-224. 